\title{
G6PT Inhibition Model Using HL-60 Cells and Induction of ROS Production through PKC/NOX2 Activation: Clinical Condition for Elucidation of Glycogen Storage Disease Type Ib
}

\author{
Daisuke Satoh, ${ }^{a}$ Mariko Ohte, ${ }^{b}$ Tohru Maeda ${ }^{a, c}$ Katsunori Nakamura, ${ }^{a, b}$ and \\ Tamihide Matsunaga*,a,b \\ ${ }^{a}$ Department of Clinical Pharmacy, Graduate School of Pharmaceutical Sciences, Nagoya City University; \\ ${ }^{b}$ Educational Research Center for Clinical Pharmacy, Faculty of Pharmaceutical Science, Nagoya City University; \\ 3-1 Tanabe-dori, Mizuho-ku, Nagoya 467-8603, Japan: and ${ }^{c}$ College of Pharmacy, Kinjo Gakuin University; 1723-2 \\ Ohmori-cho, Moriyama-ku, Nagoya 463-8521, Japan. \\ Received September 9, 2013; accepted December 26, 2013; advance publication released online January 9, 2014
}

\begin{abstract}
Glycogen storage disease type Ib (GSD-Ib) is caused by mutations in the glucose-6-phosphate transporter (G6PT) gene, which is involved in glycogen metabolism. Patients with GSD-Ib are known to develop neutropenia as a specific symptom, but the causes remain unclear. To elucidate reduced nicotinamide adenine dinucleotide phosphate (NAD(P)H) oxidase (NOX) 2-associated mechanisms in neutrophil cell membranes, we examined the mechanism of reactive oxygen species (ROS) production after differentiation from HL-60 cells, and the collapse of glycogen metabolism because of G6PT deficiency. ROS production and caspase-3 and -9 activation were observed in G6PT inhibitor-treated neutrophils but not in control cells. Suppression of ROS production by NOX2 inhibitors or protein kinase $\mathrm{C}$ (PKC) inhibitors combined with G6PT inhibitor was found to be dependent on the concentration of each inhibitor. Furthermore, ROS production, and caspase-3 and $\mathbf{- 9}$ activities were dependent on glucose concentrations. These data indicate that reduced ROS production and suppressed apoptosis in the presence of $\mathrm{PKC}$ inhibitors may reflect suppression of PKC-induced NOX2 activation. However, under low glucose conditions, ROS production was reduced and apoptosis was suppressed in neutrophils, suggesting that glucose is a substrate for initiating ROS production. In the present study, the investigation of the pathology of GSD-Ib indicated that a high intracellular glucose level leads to an increase in ROS production by PKC induction and NOX2 activation.
\end{abstract}

Key words glycogen storage disease type Ib; reactive oxygen species; apoptosis; glucose-6-phosphate transporter; nicotinamide adenine dinucleotide phosphate oxidase; protein kinase $\mathrm{C}$

Glycogen storage disease type Ib (GSD-Ib) is an inborn error of metabolism with an incidence of $1 / 100000$ and is caused by mutations in the glucose-6-phosphate transporter $(G 6 P T)$ gene (NM 001467, 11q23), which is involved in glycogen metabolism. ${ }^{1-4)}$ To date, $>80$ types of G6PT gene mutations have been reported, and in Japanese patients, the missense mutation (W118R) in the second exon reportedly accounts for $>40 \%$ of mutations. ${ }^{5)}$

G6PT is an endoplasmic reticulum (ER) membrane protein that is involved in glycogen metabolism as a transporter of glucose 6-phosphate (G6P) from the cytoplasm to the ER. ${ }^{6}$ The pathology of GSD-Ib includes hepatomegaly and renal swelling caused by accumulation of large quantities of glycogen in the liver and kidneys. Deficiencies of the G6Pase system result in decreased conversion of G6P into glucose, leading to tissue compression by glycogen and subsequent liver and kidney dysfunction. In addition, because majority of glucose is produced by hydrolysis of G6P during glycogenolysis and glyconeogenesis, deficiencies of the G6Pase system cause hypoglycemia, which compels patients with GSD-I to maintain blood glucose levels by constantly ingesting glucose or its polymers. Subsequently, decreased ratios of blood insulin to glucagon promote fatty acid release from fat tissues, which causes hyperlipidemia and fatty liver disease.

In addition, patients with GSD-Ib develop neutropenia as a specific symptom, ${ }^{7)}$ although the mechanisms remain to be elucidated. Previous reports by Kuijpers et al. ${ }^{8)}$ and Kim

The authors declare no conflict of interest et $a{ }^{9}{ }^{9)}$ show that oxidative stress and apoptosis are significantly increased in neutrophils of patients with GSD-Ib and $G 6 P T^{(-/)}$mice compared with healthy subjects and $G 6 P T^{(+/+)}$ mice, respectively. Increased apoptosis is believed to be caused by oxidative stress. ${ }^{10}$ Accordingly, treatment of patients with GSD-Ib with the vitamin E significantly improves neutropenia because of its antioxidant activity. Several reports describe the causal role of oxidative stress in neutropenic patients with GSD-Ib. However, few reports elucidate mechanisms associated with the production of reactive oxygen species (ROS). Leuzzi et al. $^{11)}$ identified a reduced nicotinamide adenine dinucleotide phosphate $(\mathrm{NAD}(\mathrm{P}) \mathrm{H})$ oxidase (NOX) 2-mediated ROS production pathway in GSD-Ib neutrophils, and showed that inhibition of G6PT led to NOX2 activation, and that a NOX2 inhibitor suppressed apoptosis. ${ }^{11)}$ Whereas this report demonstrated the role of NOX2 in ROS production, the role of G6PT deficiency in patients with GSD-Ib was not described.

In the present study, we determined the mechanisms by which collapse of glycogen metabolism because of G6PT deficiency results in the production of ROS. In this study, cytoplasmic neutrophil NOX2 activation was characterized in HL-60 human premyeloid leukemia-derived cells and the causes of GSD-Ib-mediated neutropenia were elucidated.

\section{MATERIALS AND METHODS}

Cell Culture HL-60 cells were differentiated into neutrophils by addition of $1.25 \%$ dimethyl sulfoxide (DMSO) to 
RPMI1640 medium containing 10\% fetal bovine serum (FBS), as described by Leuzzi et al. ${ }^{11)}$ Subsequently, on Day 2 of differentiation, the cells were incubated with the G6PT inhibitor 4,4-diisothiocyanostilbene-2,2-disulfonic acid (DIDS), and were harvested on Day 4 of differentiation for use in experiments. Control cells were differentiated using 1.25\% DMSO, but were cultured for $4 \mathrm{~d}$ without DIDS.

Determination of ROS Production Using L-012 DIDStreated neutrophils were washed in phosphate buffered saline (PBS) and were resuspended in RPMI1640 medium at $1 \times 10^{5}$ cells per $600 \mu \mathrm{L}$. Subsequently, $600 \mu \mathrm{L}$ cell suspensions were treated with $2 \mu \mathrm{L}$ of $20 \mathrm{~mm} 8$-amino-5-chloro-7phenylpyridol[3,4- $d]$ pyridazine-1,4- $(2 H, 3 H)$ dione sodium salt (L-012) with or without 6-hydroxy-2,5,7,8-tetramethylchroman-2-carboxylic acid (Trolox C), diphenyliodonium chloride (DPI), apocynin, 3-(1-(3-imidazol-1-ylpropyl)-1H-indol3-yl)-4-anilino-1H-pyrrole-2,5-dione (IYIAP), staurosporine, or chelerythrine. DMSO was used as a vehicle for all cell

(A)

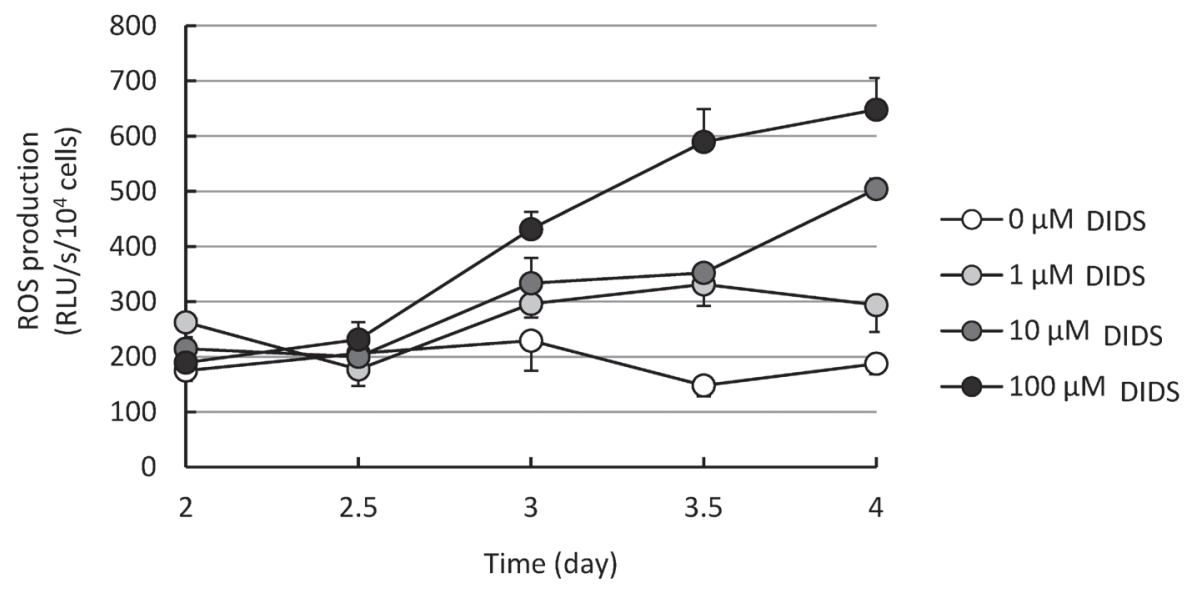

(B)

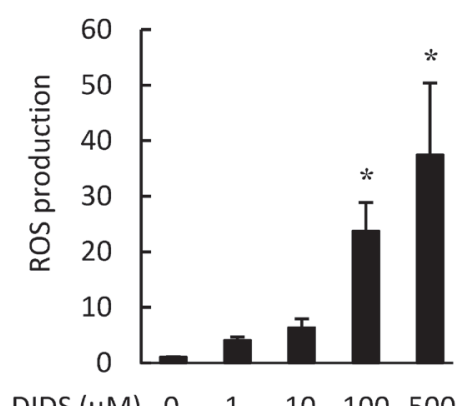

$\operatorname{DIDS}(\mu \mathrm{M}) \quad 0 \quad 1 \quad 10 \quad 100 \quad 500$
(C)

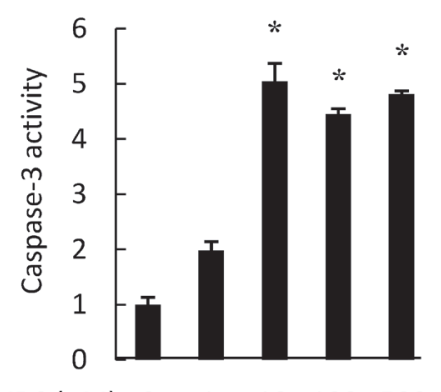

(D)

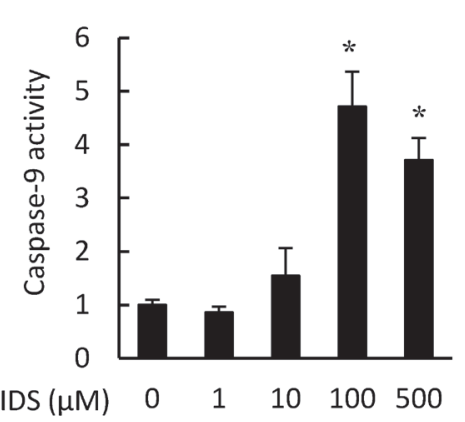

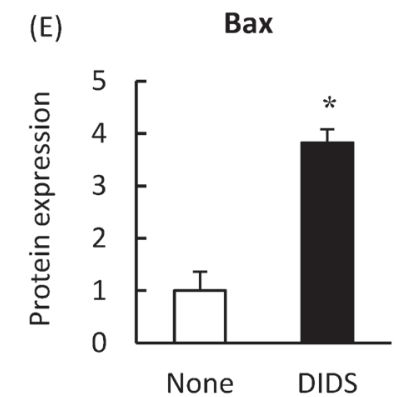

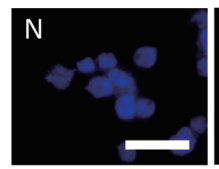

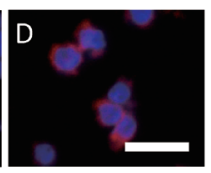

(F) Smac/Diablo
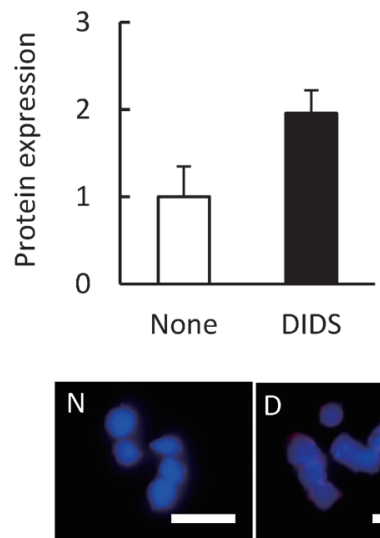

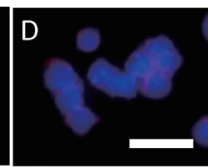

(G) Omi/HtrA2
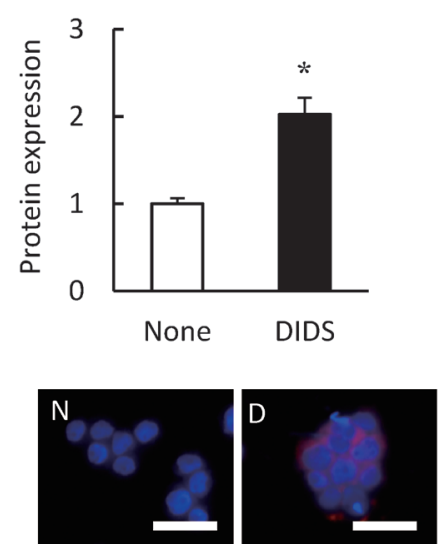

Fig. 1. Effects of DIDS on ROS Production and Apoptosis in Neutrophils

Neutrophils were incubated with 1, 10, 100, or $500 \mu \mathrm{m}$ DIDS on Day 2 of differentiation and were cultured until Day 4. (A) Time-dependent ROS production; (B) ROS production on Day 4 of differentiation; (C,D) Caspase-3 and -9 activities on Day 4; Apoptosis marker proteins (E) Bax, (F) Smac/Diablo, and (G) Omi/HtrA2. Cells in E $-\mathrm{G}$ were treated with $100 \mu \mathrm{m}$ DIDS; N, DIDS-untreated cells; D, DIDS-treated cells; red, apoptosis marker proteins; blue, DAPI. Results are expressed as the mean \pm S.E. of 4-6 independent experiments. Untreated neutrophils (None) were given a value of $1 ; \mathrm{E}-\mathrm{G} ; *{ }^{*}<<0.05 v s$. untreated neutrophils; scale bar $50 \mu \mathrm{m}$. 
treatments. Thus, control cells were treated with DMSO and DIDS. Luminol ROS assays were performed using L-012 with a luminometer (Lumat LB 9507, Berthold Technologies, Bad Wildbad, Germany).

Effects of Glucose Concentrations on ROS Production in DIDS-Treated Neutrophils Neutrophils were cultured in RPMI1640 medium containing 1, 2, 3.3, 5, or $10 \mathrm{~mm}$ glucose, $10 \%$ FBS, and $1.25 \%$ DMSO (Day 0), and $100 \mu \mathrm{M}$ DIDS was added on Day 2. Cells were harvested on Day 4 and ROS production was measured using a luminometer. Control cells were cultured in RPMI1640 containing $10 \mathrm{~mm}$ glucose, $10 \%$ FBS, and $1.25 \%$ DMSO, without DIDS.

Measurement of NOX2 Activity on Cell Membranes Cells were homogenized in cell-disruption buffer for $1 \mathrm{~min}$ using a homogenizer. The homogenate was then centrifuged at $9000 \times \mathbf{g}$ for $20 \mathrm{~min}$ and cell membrane fractions were collected by centrifugation of supernatants at $100000 \times \boldsymbol{g}$ for $60 \mathrm{~min}$. Supernatant-buffer interfaces were harvested as cell membrane fractions. All operations were performed on ice. Final protein concentrations were adjusted to $0.2 \mathrm{mg}$ protein/ $\mathrm{mL}$ according to the manufacturer's instructions. NOX2 activity was evaluated by measuring the fluorescence of L-012 after reaction with ROS, which was produced by the NOX2 coenzyme NAD $(\mathrm{P}) \mathrm{H}$. The reaction mixture contained $550 \mu \mathrm{L}$ of RPMI1640, $50 \mu \mathrm{L}$ of $0.2 \mathrm{mg}$ protein $/ \mathrm{mL}$ cell membrane fraction, and $2 \mu \mathrm{L}$ of $20 \mathrm{mM} \mathrm{L}-012$ with or without $5 \mu \mathrm{L}$ of $24 \mathrm{~mm}$ NAD(P)H. Luminol reactions with L-012 were monitored using a luminometer.

Caspase-3 and -9 Activities Caspase-3 and -9 activities were measured using commercially available kits according
(A)
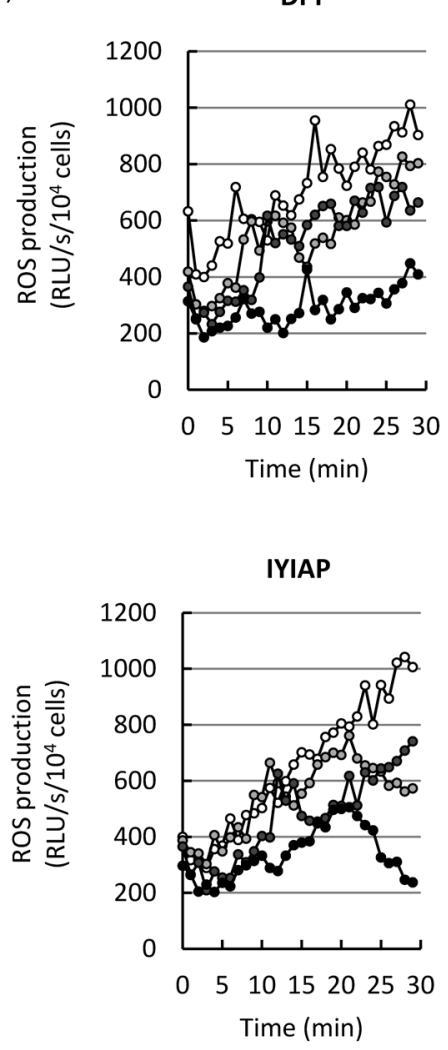

(B)

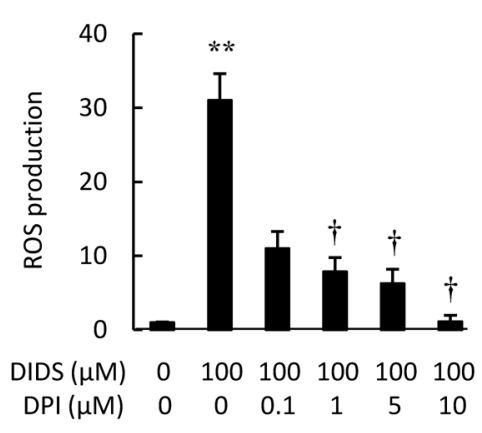

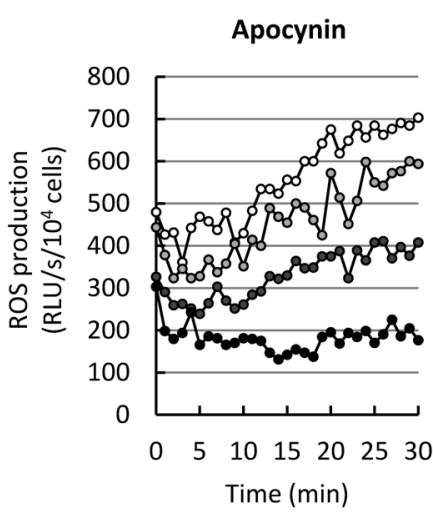
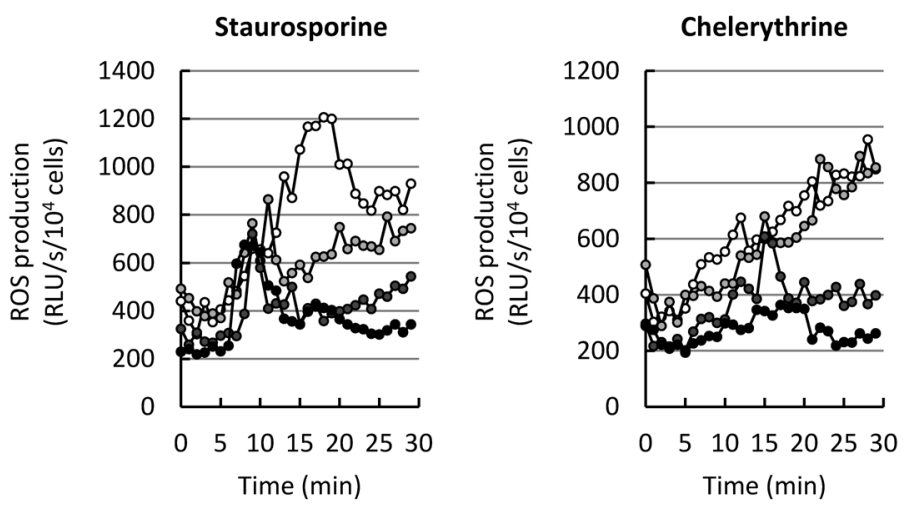

(C)

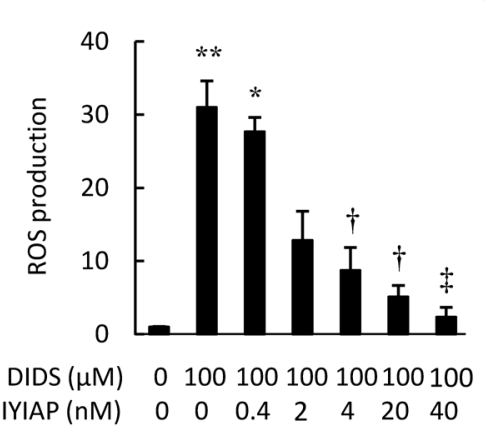

(D)

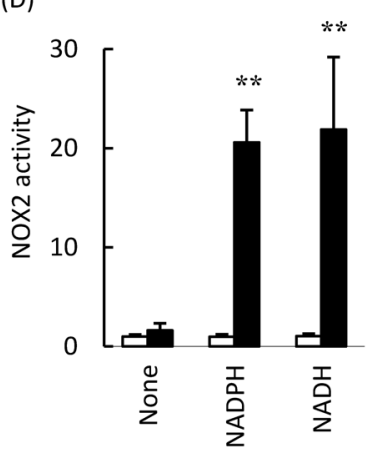

Fig. 2. Examination of ROS Production in DIDS-Treated Neutrophils

(A) DIDS-treated neutrophils were incubated with the NOX2 inhibitors DPI or apocynin, or with the PKC inhibitors IYIAP, staurosporine, or chelerythrine. ROS production after treatment with DPI (B), or IYIAP (C); NOX2 activity in cell membranes (D) was determined in the presence of $200 \mu \mathrm{M}$ NADPH or NADH in ( $\square$ ) untreated neutrophils or ( $\mathbf{\square})$ DIDS-treated neutrophils. Results are expressed as the mean \pm S.E. of $4-6$ independent experiments. Untreated neutrophils (control) were given a value of $1 ; * p<0.05,{ }^{* *} p<0.01 v s$. untreated neutrophils; ${ }^{\dagger} p<0.05,{ }^{\star} p<0.01 v s .100 \mu \mathrm{M}$ DIDS-treated neutrophils. 
to the manufacturer's instructions. These measurements were based on spectrophotometric detection of the chromophore $p$ nitroanilide $(p \mathrm{NA})$ after cleavage from the labeled substrates DEVD- $p$ NA or LEHD- $p$ NA. Cells were resuspended in $50 \mu \mathrm{L}$ of cell-disruption buffer and were subjected to three freezethaw cycles. After $20 \mathrm{~min}$ incubation on ice, suspensions were centrifuged at $10000 \times \boldsymbol{g}$ for $1 \mathrm{~min}$ at $4^{\circ} \mathrm{C}$ and supernatants were used as cytoplasm fractions. Absorbance of the chromogen $p$ NA was measured at $405 \mathrm{~nm}$ using a microplate reader according to the manufacturer's instructions.

Measurement of Apoptosis Marker Proteins Neutrophils were seeded into 96-well plates at a concentration of $1 \times 10^{4}$ cells/well. After treatments, cells were harvested by centrifugation at $1000 \mathrm{rpm}$ for $5 \mathrm{~min}$. Cells were then fixed in $100 \%$ methanol and were washed 3 times in PBS. Cells were incubated overnight at $4{ }^{\circ} \mathrm{C}$ with the following primary antibodies, diluted in PBS:Bax $(1: 100)$, Smac/Diablo $(1: 100)$, and Omi/HtrA2 $(1: 100)$. Cells were then washed 3 times in PBS and incubated with Alexa Fluor 568-conjugated anti-mouse immunoglobulin $\mathrm{G}(\mathrm{IgG})(1: 200)$ or rabbit $\mathrm{IgG}$ $(1: 200)$ for $60 \mathrm{~min}$ at room temperature. Unbound secondary antibody was removed by washing 3 times in PBS. Sample fluorescence was visualized using a fluorescence microscope, and was quantified using a fluorescence microplate-reader with excitation and emission wavelengths of 584 and $612 \mathrm{~nm}$, respectively.

(A)

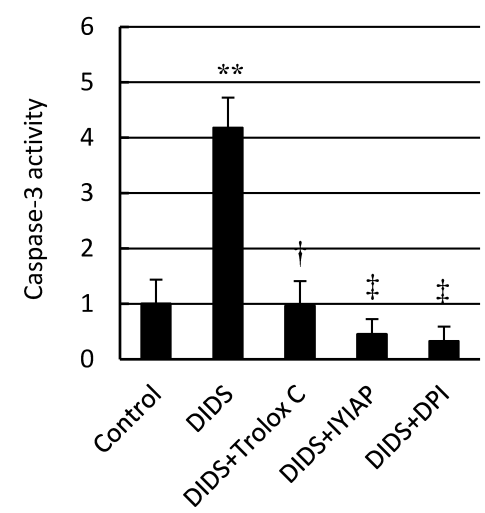

\section{RESULTS}

Effects of DIDS Treatment on ROS Production ROS production in neutrophils was evaluated after treatment with the G6PT inhibitor DIDS. Treatment with DIDS stimulated ROS production in neutrophils in a time-dependent manner (Fig. 1A). On Day 4 of differentiation, ROS production was increased by 4.0-, 6.3-, 23.7-, and 37.4-fold, in the presence of $1,10,100$, and $500 \mu \mathrm{M}$ DIDS, respectively (Fig. 1B).

Effects of DIDS Treatments on Apoptosis Cells were cultured under the same conditions as for ROS assays and were harvested on Day 4. Caspase-3 and -9 activities were increased in a DIDS concentration-dependent manner (Figs. 1C, D). Figures 1E-G show 4-, 2-, and 2-fold increased immunostaining of the apoptosis marker proteins Bax, Smac/ Diablo, and Omi/HtrA2, respectively, in $100 \mu \mathrm{M}$ DIDS-treated neutrophils compared with untreated neutrophils.

Examination of the ROS Production Pathway ROS production was increased 30-fold in DIDS-treated cells compared with control cells. Concentration-dependent suppression of ROS production was observed after treatments with the NOX2 inhibitors DPI and apocynin, and the PKC inhibitors IYIAP, staurosporine, and chelerythrine (Fig. 2A). In addition, treatments with $0.1,1,5$, and $10 \mu \mathrm{M}$ DPI reduced ROS production by $35.1 \%, 25.4 \%, 20.2 \%$, and $3.5 \%$, respectively, compared with DIDS-treated cells (Fig. 2B). Addition of $0.4,2,4,20$, and $40 \mathrm{~nm}$ IYIAP to DIDS-treated cells reduced ROS production to $89.3 \%, 41.3 \%, 28.8 \%, 16.5 \%$, and $7.6 \%$, respectively,

(B)

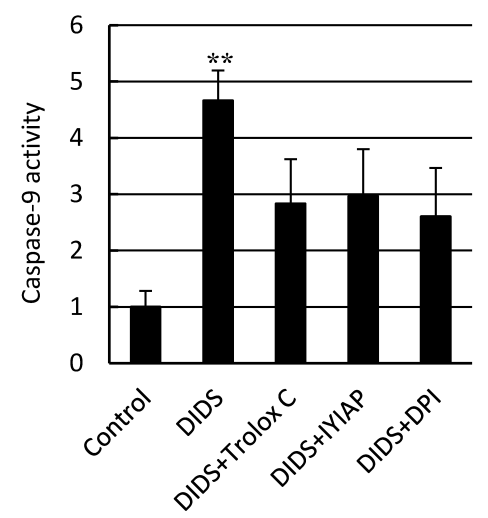

(C)

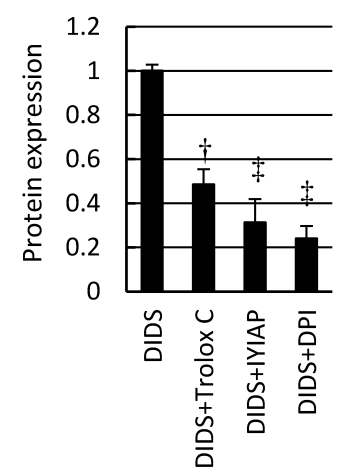

(D)

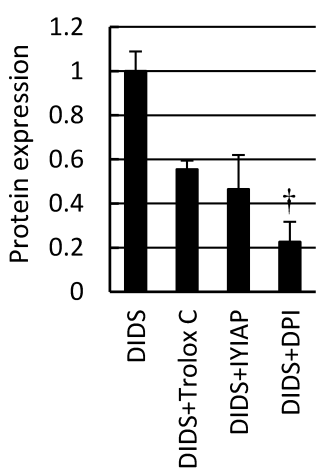

(E)

Omi/HtrA2

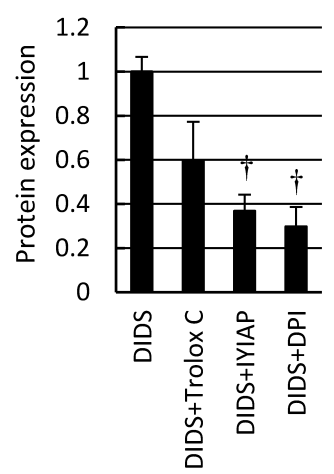

Fig. 3. Effects of ROS Inhibitors on Induction of Apoptosis in DIDS-Treated Neutrophils

DIDS-treated neutrophils were incubated for $60 \mathrm{~min}$ in RPMI1640 medium containing $10 \mu \mathrm{M}$ Trolox C, $40 \mathrm{~nm}$ IYIAP, or $10 \mu \mathrm{M}$ DPI. (A, B) Caspase-3 and -9 activities; Apoptosis marker proteins (C) Bax, (D) Smac/Diablo, and (E) Omi/HtrA2. Results are expressed as the mean \pm S.E. of 4 independent experiments. Untreated neutrophils (A, B; control) and DIDS-treated neutrophils (C-E; DIDS) were given a value of $1 ;{ }^{* *} p<0.01$ : $v s$. control, ${ }^{\dagger} p<0.05,{ }^{\ddagger} p<0.01 v s$. $100 \mu \mathrm{M}$ DIDS-treated neutrophils. 
compared with DIDS-treated cells (Fig. 2C).

ROS Production Following Activation of Cell Membrane NOX2 ROS production in cell membrane fractions was determined after addition of $\mathrm{NAD}(\mathrm{P}) \mathrm{H}$. No significant changes in ROS production were observed in the presence of $200 \mu \mathrm{M}$ NADH or $200 \mu \mathrm{M}$ NADPH to control cells. In contrast, ROS production was significantly increased by 13 - or 14-fold after addition of NADH or NADPH, respectively, in comparison with DIDS-treated control cells (Fig. 2D).

Effects of ROS Inhibitors on Apoptosis Caspase-3 and -9 activities in cells harvested on Day 4 were increased 4- and 5-fold in DIDS-treated cells compared with untreated control cells. Addition of Trolox C, IYIAP, or DPI reduced caspase-3 and -9 activities to $23.0 \%, 11.0 \%$, or $6.9 \%$, and $60.7 \%, 63.5 \%$, or $55.8 \%$, respectively, compared with DIDS-treated control cells (Figs. 3A, B).

Figures $3 \mathrm{C}-\mathrm{E}$ show the expression of the apoptosis marker proteins Bax, Smac/Diablo, and Omi/HtrA2 in DIDS-treated cells. Addition of Trolox C, IYIAP, or DPI reduced Bax, Smac/Diablo, and Omi/HtrA2 protein expression to $48.4 \%$, $31.2 \%$, or $23.9 \%, 55.3 \%, 46.3 \%$, or $22.6 \%$, and $59.6 \%, 36.8 \%$, or $29.7 \%$, respectively, compared with DIDS-treated control cells (Figs. 3C-E).

Effects of Glucose Concentrations on ROS Production in DIDS-Treated Neutrophils ROS production in neutrophils was evaluated after stimulation with DIDS in the presence of various glucose concentrations. DIDS treated-neutrophils produced ROS in a glucose concentration- and time-dependent

(A)

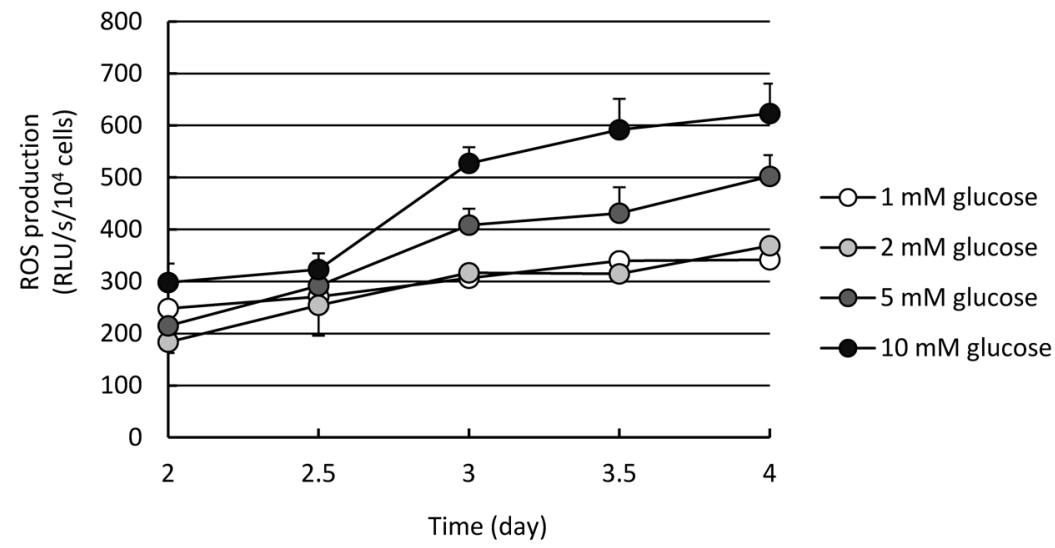

(B)

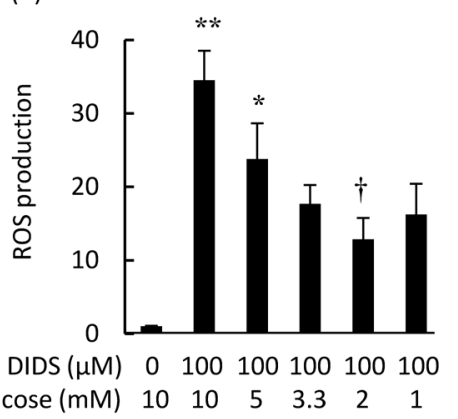

(C)

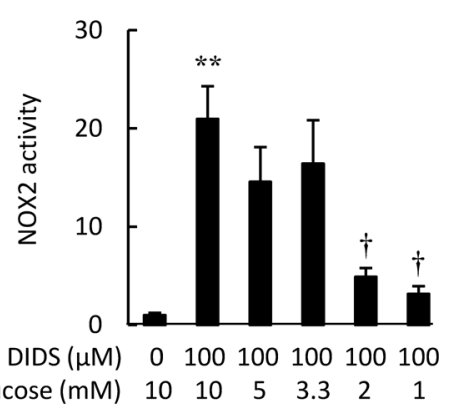

(D)

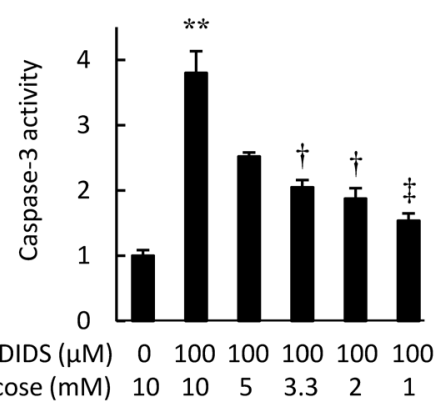

(E)

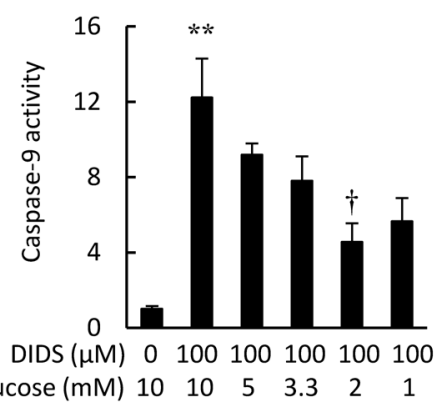

Fig. 4. Effects of Glucose Concentrations on ROS Production and Apoptosis in DIDS-Treated Neutrophils

DIDS-treated cells were cultured in RPMI1640 medium containing 1, 2, 3.3, 5, or $10 \mathrm{~mm}$ glucose until Day 4, and ROS production (A, B) and caspase-3 and -9 activities (D,E) were determined. (C) NOX2 activity in the cell membrane; Results are expressed as the mean \pm S.E. of 4-6 independent experiments. Untreated neutrophils were given a value of $1 ;{ }^{*} p<0.05,{ }^{* *} p<0.01$ vs. untreated neutrophils; ${ }^{\dagger} p<0.05,{ }^{\ddagger} p<0.01: v s$. $100 \mu \mathrm{M}$ DIDS-treated neutrophils in the presence of $10 \mathrm{~mm}$ glucose. 
manner (Fig. 4A). Moreover, reduced glucose concentrations stoichiometrically suppressed ROS production (Figs. 4A, B).

On Day 4, cell membrane NOX2 activity in the presence $200 \mu \mathrm{M}$ NADPH was dependent on glucose concentrations (Fig. 4C).

Effects of Glucose Concentration on Caspase Activities in DIDS-Treated Neutrophils On Day 4, caspase activities were significantly increased in DIDS-treated cells compared with control cells. However, caspase- 3 and -9 activities were shown to be dependent on glucose concentrations (Figs. 4D, E). Specifically, supplementation of DIDS-treated neutrophils with $5,3.3,2$, or $1 \mathrm{~mm}$ glucose reduced caspase-3 activity to $66.3 \%, 53.9 \%, 49.2 \%$, or $40.5 \%$, respectively, in comparison with that in the presence of $10 \mathrm{~mm}$ glucose (Fig. 4D). Under the same conditions, caspase- 9 activity was reduced to $75.2 \%, 63.9 \%, 37.3 \%$, and $46.3 \%$, respectively (Fig. 4E).

\section{DISCUSSION}

Neutrophils of patients and mice with GSD-Ib produce ROS without external stimuli. ${ }^{8,9)}$ To prepare a model of GSDIb neutrophils, we induced differentiation of HL-60 cells to neutrophils using the culture conditions described above and added the G6PT inhibitor, DIDS, on Day 2 of differentiation. ROS production was significantly higher in cells exposed to DIDS compared with control cells, and increased in a timeand concentration-dependent manner (Figs. 1A, B).

Caspase cysteine proteases play central roles in signal transduction during apoptosis. ${ }^{12)}$ Accordingly, caspase-3 and -9 activities and ROS production were increased in DIDS-treated differentiated HL-60 cells in a concentration-dependent manner (Figs. 1C,D). In addition, the apoptosis marker proteins Bax, Smac/Diablo, and Omi/HtrA2 were increased in these cells, ${ }^{13-16)}$ as shown in immunostaining experiments (Figs. $1 \mathrm{E}-\mathrm{G})$. Bax is a member of the pro-apoptotic Bcl-2 family, and is involved in the release of mitochondrial cytochrome $c$. Smac/Diablo and Omi/HtrA2 suppress inhibition of caspase by XIAP and promote caspase activation. As shown in Figs. $1 \mathrm{E}-\mathrm{G}$, DIDS-treated neutrophils had increased immunohistochemical fluorescence of these apoptosis marker proteins compared with untreated cells, indicating that DIDS-treated HL-60 cells are an appropriate model of GSD-Ib.

ROS production by NOX2 has been demonstrated in vivo. However, NOX2 is inactive in the absence of various soluble proteins. NOX2 plays a central role in phagocytic and bactericidal mechanisms of neutrophils, produces ROS by transferring an electron from cytoplasmic NAD(P)H to extracellular oxygen, and transduces signals following binding with $\mathrm{p} 67^{\text {phox }}$, p47 phox , and Rac in response to cellular stimuli. ${ }^{17-19)}$ In agreement with a report by Leuzzi et al., ${ }^{11)}$ ROS production by DIDS-treated HL-60 cells was reduced by treatments with the NOX2 inhibitors DPI and apocynin (Figs. 2A upper, B), and was increased in the presence of the NOX2 coenzymes $\mathrm{NADPH}$ or NADH (Fig. 2D). These data indicate that ROS production in GSD-Ib involves NOX2 in the cell membrane. Moreover, exposure of DIDS-treated neutrophils to DPI suppressed both oxidative stress and apoptosis (Fig. 3), suggesting that GSD-Ib-associated neutropenia is related to oxidative stress-induced apoptosis.

The present data also confirm that ROS production is reduced in the presence of the PKC inhibitors IYIAP, stau- rosporine, and chelerythrine (Figs. 2A lower, C), and that subsequent suppression of apoptosis is associated with reduced activation of caspases-3 and -9 (Fig. 3). PKC phosphorylates side-chain $\mathrm{OH}$ groups of serine and threonine residues, and is involved in intracellular signal transduction. Target proteins of PKC include the NOX2 isoform p47 phox ${ }^{20,21)}$ which is transferred to cell membranes with $\mathrm{p} 67^{\text {phox }}$ and Rac to form NOX2 complexes that produce ROS. ${ }^{22)}$ Hence, reduced ROS production and suppression of apoptosis in the presence of PKC inhibitors may reflect suppression of PKC-induced NOX2 activation.

In GSD-Ib, glucose is excessively utilized via the glycolytic pathway, resulting in increased glycogen synthesis and disorders of glucose release. Several mechanisms relating ROS production with high intracellular glucose levels and enhanced glycolysis have been proposed. ${ }^{23,24)}$ However, in the present study, the PKC-NOX2 system was most likely influenced by PKC activation following increased biosynthesis of diacylgricerol (DAG) from glycolytic $\alpha$-glycerophosphate. ${ }^{25,26)}$ Importantly, DAG is synthesized from G6P by glycolytic enzymes via the metabolites glyceraldehyde 3-phosphate and phosphatidic acid. ${ }^{27-29)}$

In this study, DAG levels were not measured in the GSDIb model cells. However, when these DIDS-treated cells were cultured in low glucose medium, ROS production (Figs. 4A, B) and apoptosis (Figs. 4D,E) were suppressed, indicating that glucose is used as a substrate in this process. In addition, the observed glucose concentration-dependent increase in ROS production (Fig. 4C) in NADPH-supplemented cell membrane fractions indicates involvement of membrane bound NOX2 and the DAG-PKC pathway.

In the present study, we examined the pathology of GSDIb using a DIDS-treated HL-60 neutrophil model and found that high intracellular glucose levels lead to increased ROS production through activation of the PKC/NOX2 pathway. Because the mechanism of ROS production associated with G6PT deficiency in GSD-Ib remains unclear, the results of this study provide important new information on GSD-Ib pathology.

\section{REFERENCES}

1) Chou JY, Matern D, Mansfield BC, Chen YT. Type I glycogen storage disease: disorder of the glucose-6-phosphate complex. Curr. Mol. Med., 2, 121-143 (2002).

2) Hiraiwa H, Pan CJ, Lin B, Moses SW, Chou JY. Inactivation of the glucose 6-phosphate transporter causes glycogen storage disease type Ib. J. Biol. Chem., 274, 5532-5536 (1999).

3) Gerin I, Veiga-da-Cunha M, Noël G, Van Schaftingen E. Structure of the gene mutated in glycogen storage disease type Ib. Gene, 227, 189-195 (1999).

4) Chou JY, Jun HS, Mansfield BC. Neutropenia in type Ib glycogen storage disease. Curr. Opin. Hematol., 17, 36-42 (2010).

5) Kure S, Suzuki Y, Matsubara Y, Sakamoto O, Shintaku H, Isshiki G, Hoshida C, Izumi I, Sakura N, Narisawa K. Molecular analysis of glycogen storage disease type Ib; Identification of a prevalent mutation among Japanese patients and assignment of a putative glucose-6-phosphate translocase gene to chromosome 11. Biochem. Biophys. Res. Commun., 248, 426-431 (1998).

6) Veiga-da-Cunha M, Gerin I, Van Schaftingen E. How many forms of glycogen storage disease type I? Eur. J. Pediatr., 159, 314-318 (2000). 
7) Schaub J, Heyne K. Glycogen storage disease type Ib. Eur. J. Pediatr., 140, 283-288 (1983).

8) Kuijpers TW, Maianski NA, Tool AT, Smit GP, Rake JP, Roos D, Visser G. Apoptotic neutrophils in the circulation of patients with glycogen storage disease type 1b (GSD1b). Blood, 101, 5021-5024 (2003).

9) Kim SY, Jun HS, Mead PA, Mansfield BC, Chou JY. Neutrophil stress and apoptosis underlie myeloid dysfunction in glycogen storage disease type Ib. Blood, 111, 5704-5711 (2008).

10) Melis D, Della Casa R, Parini R, Rigoldi M, Cacciapuoti C, Marcolongo P, Benedetti A, Gaudieri V, Andria G, Parenti G. Vitamin E supplementation improves neutropenia and reduces the frequency of infections in patients with glycogen storage disease type 1b. Eur. J. Pediatr., 168, 1069-1074 (2009).

11) Leuzzi R, Bánhegyi G, Kardon T, Marcolongo P, Capecchi PL, Burger HJ, Benedetti A, Fulceri R. Inhibition of microsomal glucose-6-phosphate transport in human neutrophils results in apoptosis: a potential explanation for neutrophil dysfunction in glycogen storage disease type 1b. Blood, 101, 2381-2387 (2003).

12) Gao Z, Tian Y, Wang J, Yin Q, Wu H, Li YM, Jiang X. Dimeric Smac/diablo peptide directly relieves caspase-3 inhibition by XIAP. Dynamic and cooperative regulation of XIAP by Smac/Diablo. $J$. Biol. Chem., 282, 30718-30727 (2007).

13) Moulding DA, Akgul C, Derouet M, White MR, Edwards SW BCL-2 family expression in human neutrophils during delayed and accelerated apoptosis. J. Leukoc. Biol., 70, 783-792 (2001).

14) Maianski NA, Mul FP, van Buul JD, Roos D, Kuijpers TW. Granulocyte colony-stimulating factor inhibits the mitochondria-dependent activation of caspase-3 in neutrophils. Blood, 99, 672-679 (2002).

15) Maianski NA, Roos D, Kuijpers TW. Bid truncation, Bid/Bax targeting to the mitochondria, and caspase activation associated with neutrophil apoptosis are inhibited by granulocyte colony-stimulating factor. J. Immunol., 172, 7024-7030 (2004).

16) Song $\mathrm{Z}$, Yao $\mathrm{X}, \mathrm{Wu} \mathrm{M}$. Direct interaction between surviving and Smac/DIABLO is essential for the anti-apoptotic activity of survivin during taxsol-induced apoptosis. J. Biol. Chem., 278, 2313023140 (2003).

17) Volpp BD, Nauseef WM, Donelson JE, Moser DR, Clark RA. Cloning of the cDNA and functional expression of the 47-kilodalton cytosolic component of human neutrophil respiratory burst oxidase. Proc. Natl. Acad. Sci. U.S.A., 86, 7195-7199 (1989).

18) Lomax KJ, Leto TL, Nunoi H, Gallin JI, Malech HL. Recombinant 47-kilodalton cytosol factor restores NADPH oxidase in chronic granulomatous disease. Science, 245, 409-412 (1989).
19) Wientjes FB, Hsuan JJ, Totty NF, Segal AW. p40phox, a third cytosolic component of the activation complex of the NADPH oxidase to contain src homology 3 domains. Biochem. J., 296, 557-561 (1993).

20) Heyworth PG, Badwey JA. Protein phosphorylation associated with the stimulation of neutrophils. Modulation of superoxide production by protein kinase $\mathrm{C}$ and calcium. J. Bioenerg. Biomembr., 22, 1-26 (1990).

21) El Benna J, Faust RP, Johnson JL, Babior BM. Phosphorylation of the respiratory burst oxidase subunit p47phox as determined by two-dimensional phosphopeptide mapping. Phosphorylation by protein kinase $\mathrm{C}$, protein kinase $\mathrm{A}$, and a mitogen-activated protein kinase. J. Biol. Chem., 271, 6374-6378 (1996).

22) Babior BM. NADPH Oxidase: An Update. Blood, 93, 1464-1476 (1999).

23) Inoguchi $\mathrm{T}$, Li P, Umeda $\mathrm{F}, \mathrm{Yu} \mathrm{HY}$, Kakimoto M, Imamura M, Aoki T, Etoh T, Hashimoto T, Naruse M, Sano H, Utsumi H, Nawata H. High glucose level and free fatty acid stimulate reactive oxygen species production through protein kinase $\mathrm{C}$ dependent activation of NAD(P)H oxidase in cultured vascular cells. Diabetes, 49, 1939-1945 (2000).

24) Brownlee M, Nishikawa $T$, Edelstein D, Du XL, Yamagishi $S$, Matsumura T, Kaneda Y, Yorek MA, Beebe D, Oates PJ, Hammes HP, Giardino I. Normalizing mitochondrial superoxide production blocks three pathways of hyperglycaemic damage. Nature, 404, 787-790 (2000)

25) Erickson RW, Langel-Peveri P, Traynor-Kaplan AE, Heyworth PG, Curnutte JT. Activation of human neutrophil NADPH oxidase by phosphatidic acid or diacylglycerol in a cell-free system. Activity of diacylglycerol is dependent on its conversion to phosphatidic acid. J. Biol. Chem., 274, 22243-22250 (1999).

26) Xia P, Inoguchi T, Kern TS, Engerman RL, Oates PJ, King GL. Characterization of the mechanism for chronic activation of diacylglycerol-protein kinase C pathway in diabetes and hypergalactosemia. Diabetes, 43, 1122-1129 (1994).

27) Romano AH, Conway T. Evolution of carbohydrate metabolic pathways. Res. Microbiol., 147, 448-455 (1996).

28) Dunlop ME, Larkins RG. Pancreatic islets synthesis phospholipids de novo from glucose via acyl-dihydroxyacetone phosphate. Biochem. Biophys. Res. Commun., 132, 467-473 (1985).

29) Kambayashi Y, Takekoshi S, Tanino Y, Watanabe K, Nakano M, Hitomi Y, Takigawa T, Ogino K, Yamamoto Y. Various molecular species of diacylglycerol hydroperoxide activate human neutrophils via PKC activation. J. Clin. Biochem. Nutr., 41, 68-75 (2007). 